\title{
Traditional Medicine in Twenty-first Century Spain
}

Eduardo Dopico • Jose L. San Fabian •

Eva Garcia-Vazquez

Published online: 17 April 2008

(C) Springer Science + Business Media, LLC 2008

Erratum to: Hum Ecol

DOI 10.1007/s10745-007-9146-1

The original version of this article unfortunately contained a mistake. The word "Century" was missing in the article title.

The online version of the original article can be found at http://dx.doi. org/10.1007/s10745-007-9146-1.

E. Dopico · J. L. San Fabian

Department of Education Sciences, University of Oviedo,

Oviedo, Spain

E. Garcia-Vazquez $(\bowtie)$

Department of Functional Biology, University of Oviedo,

Oviedo, Spain

e-mail: egv@fq.uniovi.es 